\title{
Altimeter dual-frequency observations of surface winds, waves, and rain rate in tropical cyclone Isabel
}

\author{
Y. Quilfen*, J. Tournadre, B. Chapron
}

Laboratoire d'Océanograhie Spatiale, Institut Français de Recherche pour l'Exploitation de la Mer, Plouzané, France

*: Corresponding author : $\underline{\text { Yves.Quilfen@ifremer.fr }}$

\begin{abstract}
Extreme weather events such as tropical cyclones are difficult to observe with conventional means. Satellite-based observations provide essential measurements of key parameters governing tropical cyclones. They are critical for short-term forecasting. Radiometers onboard the Defense Meteorological Satellite Program satellite series, WindSat and Tropical Rainfall Measuring Mission satellites, scatterometers onboard the ERS, ADEOS, and QuikScat satellites offer unprecedented synoptic observations of surface wind and atmospheric liquid water content, revealing the storm structures with good accuracy. However, satellite estimates do not provide direct measurements of geophysical parameters and can suffer from limitations linked to the sensors characteristics, such as the signal wavelength and polarization or the measurement incidence angle. For example, measurements at Ku band are strongly affected by rain. Still, each observing system can offer specific information that can be combined with the others. In particular, we highlight the capabilities of dualfrequency altimeter to provide very high resolution measurements of rain rate, surface wind speed, and wave characteristics. A method is proposed to obtain continuous along-track $5 \mathrm{~km}$ resolution measurements of these parameters in the tropical cyclone Isabel. The results shows that dualfrequency altimeters can provide useful information to complement and validate the operational fields provided by the atmospheric numerical models and by NOAA observing systems.
\end{abstract}

Keywords: Tropical cyclone / High resolution measurement / Dual-frequency altimeter / Mesearement limitations 


\section{Introduction}

Satellite-based observations are powerful means for the forecasting of tropical cyclones (TC). The Geostationary Operational Environmental Satellite (GOES) provides high resolution (about $5 \mathrm{~km} \times 5 \mathrm{~km}$ ) observations of cloud structures to estimate the Dvorak intensity (Dvorak, 1975). Polar orbiting satellites can also be used. With two satellite passes per day the instrument swath width is crucial. Over a swath width of $1400 \mathrm{~km}$, the Special Sensor Microwave Imager (SSM/I, Hollinger, 1990) observations provide estimates of rain rate and wind speed with a spatial resolution of $25 \mathrm{~km}$. Despite a relatively narrow swath (780 kilometers), the Precipitation Radar and the microwave imager onboard the Tropical Rainfall Measuring Mission (TRMM, Simpson et al., 1988) further provides unprecedented rainfall estimates in tropical cyclones. Scatterometers onboard the European Remote Sensing (ERS) satellite, Advanced Earth Observing Satellite (ADEOS) and QuikScat satellites (Tsai et al., 1999) are commonly used to determine the surface wind speed and direction at a resolution of about $25 \mathrm{~km}$. The scatterometer swath varies from $500 \mathrm{~km}$ for ERS to $1800 \mathrm{~km}$ for QuikScat. This wider swath enables two observations per day for a given tropical cyclone. However, the QuikScat Ku-band frequency (near $14 \mathrm{GHz}$ ) is very sensitive to rain, limiting the retrieved wind vector accuracy in tropical cyclones (Tournadre and Quilfen, 2003). As already demonstrated (Quilfen et al., 1998), ERS C-band (near $5 \mathrm{GHz}$ ) scatterometer measurements are little affected by rain, and provide reliable high resolution $(12.5 \mathrm{~km})$ data within a TC. Despite systematic underestimation of the hurricane winds, the $1000 \mathrm{~km}$ swath C-band scatterometers onboard the Metop satellites will thus provide invaluable surface wind observations in TCs. Finally, 
QUILFEN:

Envisat and Radarsat Synthetic Aperture Radars (SAR) complement the observations with finer resolution measurements (Katsaros et al., 2000).

The altimeter measurements are limited to nadir observations, and have almost ever been used for TC studies. However, four altimeters are currently in operation and can provide valuable high resolution $(5 \mathrm{~km})$ information when crossing a TC. Altimeters are primarily dedicated to sea surface height measurements to improve the knowledge of ocean circulation, tides, and other fields in geophysics, but estimates of significant wave height and wind speed are also obtained. The most recent altimeters (Topex/Poseidon, Envisat, Jason-1) are dual-frequency altimeters to correct for ionospheric effects, but the dualfrequency capability has also been used to detect and flag measurements affected by rain ( Quartly, 1998; Tournadre, 2004) . During storm conditions, Quartly (1997) showed that it is possible to obtain reliable significant wave height and normalized radar cross section measurements. The present study further elaborates on such results to demonstrate that reliable estimates of significant wave height, wind speed and rain rate can be obtained in tropical cyclones to complement other observations. In this study, we selected the tropical cyclone Isabel (September 2003 in the Atlantic ocean) as a test case study.

Data are described in section 2. In section 3, we analyze the rain effect on altimeter measurements. Section 4 presents the methodology to retrieve, along the altimeter track, the rain rate and the wind speed corrected for rain effects. The wind, wave and rain structures are then described in section 5. Finally, a comparison with the Hurricane Research Division (HRD/NOAA) data is shown in section 6 and conclusions are given in section 7 . 


\section{Data}

\subsection{Jason-1 altimeter data}

The Jason-1 altimeter (Ménard et al., 2003) Geophysical Data Records (GDR) and Scientific Data Records (SDR) are processed by the Aviso center in Toulouse under the responsability of the Centre National d'Etudes Spatiales (CNES) and the National Aeronautics and Space Administration (NASA). The GDR contain the geophysical parameters and the SDR contain the altimeter waveforms used to compute high resolution measurements. The Poseidon-2 altimeter is the main instrument on the Jason- 1 mission. It operates at two frequencies $(13.6 \mathrm{GHz}$ in the $\mathrm{Ku}$-band, $5.3 \mathrm{GHz}$ in the C-band) to determine ionospheric electron content, which affects the radar signal path delay. The Jason-1 Microwave Radiometer (JMR) measures water vapor content in the atmosphere to correct the atmospheric signal propagation. It collects radiation reflected by the oceans at frequencies of $18.7,23.8$, and $34 \mathrm{GHz}$.

Altimeter tracks intersecting the TC Isabel have been selected using a systematic screening through the Hurricane Research Division (HRD) fields. These fields locate the TC center to few tens of kilometers. A first selection keeps all altimeter tracks crossing the TC within $100 \mathrm{~km}$ from its center. A second selection is made by checking that the altimeter along-track wind speed profiles contain wind speed measurements above $25 \mathrm{~ms}^{-1}$ together with the lowest wind speed area near the center. Two Jason tracks have thus been selected which correspond to the mature and decaying stages of the TC, table 1 . The corresponding altimeter tracks are displayed in Figure 1 together with the Isabel best track provided by the HRD. 


\subsection{National Oceanic and Atmospheric Administration data}

The National Oceanic and Atmospheric Administration (NOAA) hosts the National Hurricane Center (NHC) and the Hurricane Research Division (HRD). The HRD has defined an experimental wind analysis tool to provide regular high resolution wind fields for tropical cyclones (Powell et al., 1998). The HRD wind analysis uses available surface weather observations (e.g., ships, buoys, coastal platforms, surface aviation reports, reconnaissance aircraft data adjusted to the surface, etc.). This includes the QuikScat scatterometer data. Depending on the quality control performed on these data (especially on rain flags), the analysis is more or less dependent on QuikScat. All data are processed to conform to a common framework for the averaging time period. The analysis provides the maximum sustained 1-minute wind speed. Because of the limited coverage of the aircraft flights and the smoothing effect of the analysis process, many details of the surface winds are probably filtered out. HRD also gives access to many other data-sets available at http://www.aoml.noaa.gov/hrd/Storm_pages/isabel2003/. Hurricane Isabel was a long-lived Cape Verde hurricane that reached Category 5 status on the Saffir-Simpson Hurricane Scale. A complete description of Isabel can be found on the NHC's web site (http://www.nhc.noaa.gov) and the best track used in this study comes from the HURDAT re-analysis project (Landsea et al., 2004).

\section{The rain effect on normalized radar cross-section measurements}

Raindrops within the atmosphere have three potential effects on microwave signals. First, a volume-scattering effect increases the total power backscattered to the altimeter. Second, a signal absorbtion causes an attenuation of the total signal. Third, raindrops striking the ocean surface can alter the surface roughness and hence the radar cross 
section (NRCS). More indirectly, rain may also affect the surface stress and the near surface wind speed, as well as to leave fresh water at the sea surface to also modify the NTCS. The attenuation and volume-scattering effects have been widely studied. Based on the Mie scattering theory, several formulations are available [Marshall and Palmer, 1948; Ulaby et al., 1981]. The Ku-band measurements are much more affected than Cband measurements (Jason and Topex/Poseidon altimeters), and S-band measurements (Envisat altimeter). This wavelength sensitivity is now routinely used to define altimeter rain flag. The Jason rain flag (Tournadre, 2004) is based on the detection of occurrences for which the measured backscatter at Ku-band is significantly attenuated compared to the expected value that can be inferred from the measured C-band backscatter. The rain flag further uses estimate of the liquid water content given by the JMR radiometer.

The Figure 2 illustrates the rain effect on the $\mathrm{Ku}$-band measurements and the rain flagging principle. The mean $\mathrm{Ku} / \mathrm{C}$ band relationship, as determined from rain-free measurements of many Jason cycles, is superimposed (red line) to measurements for the two Jason selected tracks. The lower NRCS is associated to rougher marine surface and higher local wind. NRCS measurements are close to the mean relation for C-band NRCS values down to about $13 \mathrm{~dB}$. Beyond this value, Ku-band measurements are apparently strongly attenuated. The colour scale features the liquid water content as measured by the JMR radiometer. The attenuated measurements correspond to points for which the liquid water content is greater than $1 \mathrm{~kg} \mathrm{~m}^{-2}$. An effective criteria, providing the minimum false alarm rate, is to flag the data for which the JMR liquid water content is above $0.2 \mathrm{~kg}$ $m^{-2}$ and for which the Ku-band NRCS measurement lies beyond 1.8 standard deviation from the mean $\mathrm{Ku} / \mathrm{C}$ band relationship. An extended validation is given in Tournadre 
(2004). For the two selected tracks, most of the points below $13 \mathrm{~dB}\left(\sim 18 \mathrm{~m} \mathrm{~s}^{-1}\right)$ shall then be discarded. It means that these altimeter NRCS and estimated winds cannot be used whereas they should be the most interesting for TCs study.

Figures 3 and 4 present the operational altimeter measurements for the two tracks. The Ku-band NRCS exhibit much larger variations than the C-band ones. Increasing wind speed is responsible for the large drops in both $\mathrm{C}$ and $\mathrm{Ku}$-band NRCS, but larger attenuation are found for Ku-band NRCS in presence of rain, as expected from Figure 2. These large variations in Ku-band NRCS for the orbit 152 (Figure 4), between 32 and 34 degrees of latitude, certainly result from the well known cyclone rainbands. The fact that the C-band NRCS does not exhibit the same variations somehow confirms that the C-band measurements are almost not affected by rain. The bottom plots, Figure 3 and Figure 4, show the impact on the wind speed retrieval. The wind speed algorithm relies on the Ku-band measurements. The first algorithms were indeed developed for mono-frequency $\mathrm{Ku}$-band altimeters (Geosat, Seasat), and it is also expected that $\mathrm{Ku}$-band measurements are more sensitive to surface wind speed. The significant wave height (Figures 3 and 4 ) is given for rain-free data (points) while the wind speed has been evaluated everywhere along the track disregarding the rain flags. From the significant wave height record, the rain strongly precludes interesting analysis. Looking at the wind speed, some information can be retrieved about the cyclone center and maximum wind locations, but with low confidence. Indeed, it is obvious that the apparent wind speed variability between 32 and 34 degrees of latitude in orbit 152 is mainly due to rain. As presented below, the C-band can be used to heuristically correct the $\mathrm{Ku}$-band measurements affected by rain, to then infer more reliable wind information in the rain areas. 


\section{Estimation of the rain rate and rain-corrected NRCS profiles}

The attenuation coefficient by rain can be expressed using the classical Marshall Palmer (1948) relationship:

$$
k=a R^{b}
$$

where $k$ is the absorption coefficient in $\mathrm{dB} k m^{-1}, R$ is the rain rate in $\mathrm{mm} h r^{-1}, a$ and $b$ are radar frequency dependent coefficients. The total attenuation (A), for a two-way path, then follows:

$$
A=2 k h=2 h a R^{b}
$$

where $h$ is the rain column height. This height has been estimated constant, $5 \mathrm{~km}$, from the TRMM bright band altitude. This band can indeed be considered as representative of the freezing level and was found almost constant within the TCs [Harris et al, 2000]. The rainfall rate is thus calculated as follows:

$$
R=\left(\frac{A}{10 a}\right)^{1 / b}
$$

The $a$ and $b$ coefficients used in this study are given by Tournadre (2004):

$$
a=34.610^{-3} \quad b=1.109
$$

for Ku-band, and

$$
a=1.0610^{-3} \quad b=1.393
$$


for C-band.

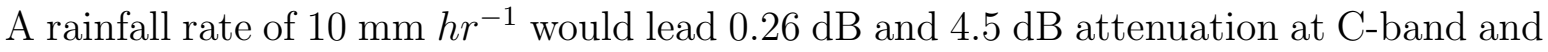
Ku-band, respectively. A first estimate of Ku-band NRCS attenuation is computed from the difference between the actual Ku-band measurement and its expected value evaluated using the $\mathrm{C}$-band measurement and the $\mathrm{Ku} / \mathrm{C}$ rain-free relationship. A rain rate estimate is then deduced using Equation 3. The C-band attenuation is then computed using Equation 2 to obtain a corrected C-band NRCS. A new Ku-band attenuation is then estimated and the process is iterated until the corrected $\mathrm{Ku}$ and $\mathrm{C}$ band NRCS reach stable values within $0.1 \mathrm{~dB}$. Figure 5 displays the $\mathrm{Ku}$ and $\mathrm{C}$ band attenuation values for the two selected Jason orbits. The Ku-band attenuation can reach 6 dB while the C-band one remains below $0.5 \mathrm{~dB}$. Figure 6 displays the measured and corrected NRCS. The $\mathrm{C}$ band signal is only slightly modified, with only small changes near the NRCS minima for orbit 50 , and between $32^{\circ}$ and $34^{\circ}$ of latitude for orbit 152 . In these areas, the Ku band signal is strongly attenuated, corresponding to the heaviest rain within TC Isabel. The corrected Ku-band NRCS is now more regular. However, the corrected Ku-band signal amplitudes still exhibit larger variations than the C-band ones. For orbit 50, there is a 3 $\mathrm{dB}$ difference for $\mathrm{C}$-band and $4.5 \mathrm{~dB}$ for $\mathrm{Ku}$ band between the minimum and maximum NRCS, corresponding to the TC area of maximum wind and the TC center, respectively. This also holds for orbit 152. This reflects the Ku-band greater sensitivity to surface conditions in tropical cyclones, as discussed in section 5.1. Once corrected, the Ku-band is more adapted for the observation of extreme conditions. These results are used in the following section to infer the wind speed, rain rate, and wave height continuously along the two Jason tracks. 


\section{Surface wave, wind, and rain structures in TC Isabel}

The rain rate can be estimated using the methodology described in the previous section. The significant wave height is readily obtained using C-band waveform analysis. The wind speed can be estimated using the corrected Ku-band NRCS. It must be precised that errors for these parameters are not independent. Rain not only impacts the Ku-band NRCS measurements but also affects the significant wave height (SWH) measurements. As shown by Tournadre (1998), rain can strongly modify the shape of Ku-band altimeter waveforms. It can be seen in Figure 7 where large peaks signal erroneous Ku-band SWH estimates. The C-band SWH shall not be affected. As already shown by Quartly (1998), this is correct for Jason but this does not hold for Topex. Contrary to Jason which has two independent trackers for the $\mathrm{C}$ and $\mathrm{Ku}$ bands, the Topex $\mathrm{C}$-band indeed uses the Ku-band tracker.

\subsection{Approach to wind speed evaluation}

Recent developments have been done (Gourrion et al., 2000; Chen et al., 2002 ) to take into account the apparent significant wave height signature in NRCS measurements. Former models (Chelton et McCabe, 1985, Witter et Chelton, 1991) were based on a univoque relationship between the surface wind speed and the altimeter NRCS, while observations clearly reveal that different NRCS values can be obtained for a given surface wind speed, depending on the sea state degree of development, or wave age. However, while giving some improvements over former models for normal conditions, the Gourrion et al. (2000) model accuracy is questionable in case of tropical cyclones where high wind and sea state conditions are dominating. As illustrated in Figure 7, the wind field structures moving quickly over the sea surface generate complex wave fields with marked asymmetries. 
QUILFEN:

Furthermore, questions remain to interpret radar cross section variations related to the injection of sea droplets into the atmospheric boundary layer as well as intense and related sea surface disruption and sea bubble generation. A quick look at photos taken from aircraft (see http://www.aoml.noaa.gov/hrd/Storm_pages/isabel2003/photo.html) shows that the sea surface is widely covered by whitecaps and foam. As already studied (Zheng et al., 1983), the microwave reflectivity may strongly be impacted by foam layers and whitecap coverage. As consistently derived (Reul and Chapron, 2003), increasing winds will also increase both the average foam coverage and foam thickness. According to the theory of electromagnetic waves propagating in stratified media, the total thickness increase will induce the total reflectivity to decrease with increasing wavelength, i.e. the Ku-band is anticipated to be more attenuated than C-band. Furthermore, sea spray production is also likely to increase and saturate the atmospheric boundary layer under hurricane conditions. While sea spray production may alter the turbulent kinetic energy and turbulence in the atmospheric boundary layer (e.g Andreas, 2004) to modify the overall stress at the surface, the droplet size and concentration may also impact the electromagnetic reflectivity. As for the rain attenuation, this new phase medium consisting of air and water is likely to attenuate more significantly $\mathrm{Ku}$-band than $\mathrm{C}$-band nadir microwave measurements. This is apparently confirmed over the selected Jason tracks, and is also systematically observed from the mean $\mathrm{Ku} / \mathrm{C}$ relationship from moderate to high wind speeds (Chapron et al., 1995; Elfouhaily et al., 1998). Firstly assumed to be associated to changes in surface roughness, the observed increased sensitivity for $\mathrm{Ku}-$ band measurements should also likely include foam and sea spray effects linked to air flow separation and wave breaking events. 
To empirically account for these effects, we use for the present study a mixed Ku-band altimeter wind speed algorithm based on the standard Gourrion et al. algorithm (2000) for wind speed lower than $20 \mathrm{~m} \mathrm{~s}^{-1}$, and on the Young's algorithm (1993) for winds greater than $20 \mathrm{~m} \mathrm{~s}^{-1}$. The Young's algorithm was calibrated using the Ku-band Geosat altimeter measurements in tropical cyclones. This algorithm is a simple univoque relation between the surface wind speed and the NRCS, defined for winds greater than $20 \mathrm{~m} \mathrm{~s}^{-1}$. The Young's algorithm is defined as:

$$
V=72-6.4 *\left(\sigma_{0}^{K u}+C^{t e}\right)
$$

where $\sigma_{0}$ is the $\mathrm{Ku}$-band NRCS corrected for rain effects, and $C^{t e}$ is an arbitrary chosen constant to match the Gourrion et al. algorithm at $20 \mathrm{~m} / \mathrm{s}$.

For C-band, the proportionality constant in Equation (6) can be derived by fitting the retrieved wind speed profile. As found, the cross section difference between $\mathrm{C}$ and $\mathrm{Ku}$ linearly increases with wind speed as:

$$
\sigma_{0}^{C}-\sigma_{0}^{K u} \propto V / 32
$$

While relatively weak, such a differing sensitivity is consistenly found. If mostly attributed to the effect of oceanic whitecaps, the foam coverage is the same and this sensitivity shall only relate to differences between $\mathrm{Ku}$ and $\mathrm{C}$ band reflectivity sensitivity to the mean foam thickness. Foam thickness is naturally distributed according to the range of surface wave scales involved in breaking processes. At high wind speeds, longer scales are breaking and foam layers are on average thicker with increasing wind speed. 
As for rain attenuation, the C-band shall be little affected by the foam thickness. Foam coverage shall then be of first order impact to explain C-band sensitivity. If we consider the roughness sensitivity to be saturated in case of very high winds, the C-band decay can be explained by an effective whitecap coverage as:

$$
W=C e^{-\beta V}
$$

where $\beta=1 / 35, V$ is the wind speed. $C$ is a constant defined to match already reported whitecap coverages around 20 m/s, e.g. Monahan and O'Muircheartaingh (1980), Bondur and Sharkov (1982). Equation 8 is derived from Equation 6 for C-band. As illustrated Figure 8, the deduced effective coverage appears consistent with the other published empirical relationships.

\subsection{Results}

Figure 9 summarizes the results for wind speed, wave height, and rain rate for the two Jason orbits. Two orbits sampled the TC eye characterized by a rain-free area with lower winds. The cyclone was moving northwestwardly. The altimeter thus first sampled the rear-left quadrant, then the front-right one for both orbits (Figure 9, x-axis). Strong asymetries in the measured parameters are found. The greatest differences are for the SWH parameter. For orbit 50, SWH reaches 14.7 meters and 11 meters on both sides of the eye, and the corresponding maximum wind speeds are $49 \mathrm{~m} \mathrm{~s}^{-1}$ and $45 \mathrm{~m} \mathrm{~s}^{-1}$, respectively. For orbit 152, SWH reaches 12.4 meters and 7.3 meters on both sides of the eye, and the corresponding maximum wind speeds are $35 \mathrm{~m} \mathrm{~s}^{-1}$ and $31 \mathrm{~m} \mathrm{~s}^{-1}$, respectively. Extreme high sea states and winds are known to occur to the right of the direction of 
movement in typhoons (Willoughby and Rahn, 2004), as verified with these altimeter measurements.

Two distinct rain areas associated with these maximum winds are usually encountered in tropical cyclones, where the eyewall area and the rainbands are associated with surface wind convergence. For orbit 50, the broader rainband lies on the southern side while the maximum wind area is on the northern side. Aircraft radar data (see http://www.aoml.noaa.gov/hrd/Storm_pages/isabel2003/) indicate that the maximum rain areas moved very quickly around the cyclone eye. It is thus difficult to compare the altimeter rain estimates with validated data for time differences greater than few hours. No HRD radar or TRMM radiometer data are close enough to perform a meaningful quantitative validation, but HRD radar reflectivity patterns in hurricanes provide a qualitative comparison and an order of magnitude of rain rate in tropical cyclones (Jorgensen and Willis, 1982; Black et al., 1994). In intense hurricanes, radar reflectivities reach about $50 \mathrm{~dB}(\mathrm{Z})$, equivalent to $74 \mathrm{~mm} / \mathrm{hr}$ rainfall rates. Less extreme reflectivities, about $40 \mathrm{~dB}(\mathrm{Z})$, characterize more convective rainfall in the eyewall and spiral bands, equivalent to $13 \mathrm{~mm} / \mathrm{hr}$ rainfall rates. Such intense convection only occupies a small fraction of the hurricane's area. Outside convection, reflectivities are also weaker, about $30 \mathrm{~dB}(\mathrm{Z})$, equivalent to $2.4 \mathrm{~mm} / \mathrm{hr}$ rain rate close to the altimeter rain detection threshold. Our present altimeter rain rate estimates are in good agreement with these values, i.e. the HRD radar reflectivities in Isabel at http://www.aoml.noaa.gov/hrd/Storm_pages/isabel2003. Furthermore, Lonfat et al. (2004) studied precipitation distributions from the TRMM/TMI and a collection of 260 TCs. As reported, the maximum rain rate observed by TMI is about $50 \mathrm{~mm} \mathrm{hr}^{-1}$ with a frequency of about $1 \%$. The heavy rainfall $(\mathrm{R}>10 \mathrm{~mm}$ 
QUILFEN:

$\mathrm{hr}^{-1}$ ) covers about $15 \%$ of the inner core area but contributes to $50 \%$ of the total rainfall amount. These heavy rainfalls are of the same order of magnitude as the maximum rainfall measured by the altimeter. As also discussed, the rainfall asymmetry is found to shift with increasing intensity. Stronger the TC, more axisymetric is the inner core. This is apparently verified in Figure 9, with a more symetric rainfall field during the stronger stage of Isabel, orbit 50. Lonfat et al. (2004) further reported that the maximum rainfall remains in front of the TC center at all speeds. This is confirmed for altimeter orbit 152 but not for orbit 50 . The rule proposed by the authors does not seem to hold when looking at the radar reflectivities on September 13th. According to very few radar images, the maximum reflectivities are indeed measured in the rear side of Isabel . Our results show that the altimeter measurements can retrieve the rainfall rate associated to convection in the eyewall and rainbands, but that the maximum rain rates occuring in the most intense convection cells are apparently smaller due to the altimeter ground resolution. The spatial scales of the rain field are often smaller, especially for the highest rates, than the nominal altimeter resolution $(\sim 5 \mathrm{~km})$.

To further analyze the rain rate variability, the individual altimeter waveforms (Scientific Data Record provided by AVISO) have then been processed to derive the rain rate every 260 meters. Figure 10 displays the obtained rain rate at low and high resolution for the two Jason orbits near the Isabel core. High resolution rain rates are now found to be larger by several $\mathrm{mm} \mathrm{hr}^{-1}$ to reach $20 \mathrm{~mm} \mathrm{hr}^{-1}$ for orbit 50 . Beyond this value, the $\mathrm{Ku}$-band altimeter waveforms are strongly distorted. Data are thus unusable in the most intense rain events as indicated in Figure 10 where gaps occur. However, the rain rate variability is nicely reproduced almost everywhere near the TC core. 
QUILFEN:

To summarize, a dual-frequency altimeter instrument can provide the tropical cyclones characteristics despite its limited unidimensional field of view. It can locate with good accuracy the tropical cyclone eye, as the rain-free area, well defined on the two Jason orbits. An estimate of the Isabel eye diameter from the altimeter rain profile can then be given. It corresponds to the inner core within the eyewall, where the downward airflow is associated with a rain free atmosphere. For orbit 50, there are 8 Jason rain-free consecutive samples within the eye, corresponding to about 45 kilometers. For orbit 152, there are 14 Jason rain-free consecutive samples within the eye, corresponding to about 80 kilometers. This is consistent with the Isabel evolution, from a relatively small intense category 5 hurricane for orbit 50 to a large decaying category 2 hurricane for orbit 152 . It is also possible to give an estimate of the radius of maximum winds, an important feature of a TC, from the wind speed profile. For orbit 50, the radius of maximum winds is about $40 \mathrm{~km}$, close to the $35 \mathrm{~km}$ estimated from the HRD wind analysis. For orbit 152, the radius of maximum winds is about $80 \mathrm{~km}$, while the HRD estimate is $115 \mathrm{~km}$. These different TC scales are again consistent, even if there are unknown errors associated to the unidimensional altimeter field of view.

In the following section, a more detailed comparison of the altimeter wind speed profiles is performed with the HRD wind data. HRD is doing a regular wind analysis on a 3-hour basis to be compared with the altimeter data with a time difference better than $1 \mathrm{~h} 30$.

\section{Comparison with the HRD wind analysis field}

The HRD wind analysis is the best available wind field, including most existing observations. Altimeter data are independant data, not assimilated in the HRD analysis. 
QUILFEN:

Another interesting feature is that both fields have very similar spatial resolution, i.e 5 $\mathrm{km}$ for the altimeter and $6 \mathrm{~km}$ for the HRD fields.

Figure 11 displays the two Jason orbits with the HRD wind analysis at the times before and after the Jason time. A red point indicates the TC center location at the Jason time, estimated from the center locations given by the HRD analysis. We did not interpolate the HRD wind field itself to avoid to blur the wind structures. For orbit 50, the Jason time is 23:51 on September 13th and the HRD times are 19:30 and 01:30 on September 13th and 14th, respectively. Time differences between Jason and the HRD field are 04:21 and 01:39. The HRD field at 22:30 on September 13th is not available. For orbit 152, the Jason time is 23:25 on September 17th and the HRD times are 22:30 and 01:30 on September 17th and 18th, respectively. Time differences between Jason and the HRD field are 0 h55 and $2 \mathrm{H} 05$. The Jason tracks cross Isabel very near its center. The HRD wind fields are the closest to Jason at 01:30 on September 14th for orbit 50, and at 22:30 on September 17 for orbit 152. A visual shift of these two fields at the estimated center location can be used to appreciate the TC areas that Jason crossed. For orbit 152, the HRD wind field is almost perfectly located at the Jason time, thanks to the small time difference.

Figure 12 compares the wind profile along the Jason tracks for the altimeter and the HRD fields before and after the Jason pass. As expected, the figure shows that the altimeter wind profile is in better agreement with the HRD field closer in time, i.e the 01:30 field on September 14th for orbit 50, and the 22:30 field on September 17th for orbit 152. Only these two HRD fields are considered in the following discussion. For orbit 50, the correlation between the HRD and Jason wind speed is nearly perfect, with the 
minimum and maxima located at the same place. It must be noted that the HRD winds are one minute averages while the Jason winds are ten minutes averages. It may explain the difference in magnitude for the higher winds, the difference vanishing as expected for lower winds. Using appropriate gust factors, the maximum one minute wind over a ten minutes interval is about $10-12 \%$ higher than the ten minutes mean wind (Powell et al, 1996). The differences between the altimeter and the HRD fields are consistent with this concept. The HRD wind speed in the Isabel center is larger because of the time difference between the Jason and HRD fields so that the displayed HRD profile does not cross exactly the TC center. Both Jason and HRD fields feature an axisymmetric wind field as expected for category $4 / 5$ hurricanes. For orbit 152 , the colocation is better for the HRD field at 22:30 and the correlation between the wind fields is good. The wind minimum in the TC center, as featured by Jason and HRD, agrees very well. Both fields present asymmetric wind fields that characterize large TCs at decaying stage. Differences between the two wind profiles are also seen. The Jason altimeter features higher winds over a larger area at the front of Isabel while the HRD indicates higher winds on a larger area at the rear side. As the cyclone is approaching the coast, it is important to get an accurate view of the wind, wave, and rain fields. Our analysis shows that the altimeter may help since the disagreement between the HRD and Jason fields could be due to limited data coverage to derive the HRD wind analysis. Indeed, good confidence can be given to high resolution $\mathrm{C}$ and $\mathrm{Ku}$ band measurements which reflects the wind speed variability along the altimeter track. The altimeter data, corrected for rain, can thus complement others means to improve or validate the HRD analysis. 


\section{Conclusions and perspectives}

The capabilities of dual-frequency altimeters are certainly going beyond its foreseen initial use. As demonstrated in this study, the dual-frequency Jason altimeter measurements can be used to derive reliable observations for surface wind, wave, and rain rate parameters in extreme conditions encountered in tropical cyclones. The wind measurements provided in the Jason GDR products are usually hardly defined in such conditions. This is due to the presence of rain that strongly affects the Ku-band signal used to derive the wind speed. The C-band channel is little affected by rain. The difference between $\mathrm{C}$ and $\mathrm{Ku}$-band then corresponds roughly to the rain rate. An iterative method is then used to estimate the rain rate together with $\mathrm{C}$ and $\mathrm{Ku}$-band radar cross section corrected for rain attenuation. Given this rain free radar cross section, measurements further reveal sufficient wind speed sensitivity at very high winds. The sensitivity is found to be larger at Ku-band than at C-band. As suggested, increasing whitecapping and sea spray production likely to occur in severe conditions can explain the measured $\mathrm{Ku}$ and $\mathrm{C}$ band sensitivity to the extreme winds encountered in tropical cyclones. Using an empirical model, the corrected rain free $\mathrm{Ku}$-band radar cross section is used to estimate a local wind speed.

As demonstrated, it is thus possible to compute wind speed and rain rate from dualfraquency measurements, continuously along the altimeter track with a $5 \mathrm{~km}$ resolution. Comparison with the Hurricane Research Division data shows good agreement for the surface wind speed and rain rate. The C-band channel is used for significant wave height measurements as long as it uses its own tracking algorithm to process C-band waveforms little affected by rain. 
Despite its very coarse spatial coverage, the proposed methodology has been shown to retrieve the main cyclone features and to pick up nicely the wind, wave and rain rate variability through a cyclone. In spite of good agreements with the HRD wind analysis, sensitivity of the method in term of surface wind and rain rate accuracy is still to be quantified. This will require to collect more TC cases and observations.

Acknowledgments. This study was supported by the European Space Agency in the frame of the "Retrieval of extreme low surface pressure using altimeters" and "Extreme Weather Events" projects. The authors are grateful to Hurricane Research Division (NOAA) for the large data base available through their web site.

\section{References}

Andreas E. L., Spray stress revisited, J. Phys. Ocean.,34, 6, 1429-1440, 2004.

Black R. A., H. B. Bluestein, and M. L. Black, Unusually strong vertical motions in a Caribbean Hurricane. Monthly Weather Review, 122, 12, 27222739, 1994.

Bondur V. G., and E. A. Sharkov, Statistical properties of whitecaps on a rough sea, Oceanology, 22, 274-279, 1982.

Chapron B., K. Katsaros, T. Elfouhaily, and D. Vandemark, A note on relationships between sea surface roughness and altimeter backscatter. 3rd Int. Symp. Air-Water Gas Transfer, Heidelberg Univ., ed. by B. Jahne and E. C Monahan, 868-878, AEON Verlag, Hanau, Germany, 1995.

Chelton and McCabe, A review of satellite altimeter measurement of surface wind speed: With a proposed new algorithm. J. Geophys. Res., 90, 1985, 4707-4720, 1985. 
QUILFEN:

Chen G., B. Chapron, R. Ezraty, and D. Vandemark, A dual-frequency approach for retrieving sea surface wind speed from TOPEX altimetry. J. Geophys. Res., 107, 3226, doi:10.1029/2001JC001098, 2002.

Dvorak, V., Tropical cyclone intensity analysis and forecasting from satellite imagery. Mon. Wea. Rev., 103, 420-430, 1975.

Elfouhaily T., J. Gourrion, B. Chapron and D.Vandemark, Estimation of wind stress using dual-frequency TOPEX data. J. Geophys. Res., 103, 25101-25108, 1998.

Gourrion J., D. Vandemark, S. Bailey, B. Chapron, Satellite altimeter models for surface wind speed developed using ocean satellite crossovers. IFREMER Tech. Report, DRO/OS-00/01, 2000.

Harris Jr., G. N., K. P. Bowman and D.B. Shin, Comparison of freezing-level altitudes from the NCEP Reanalysis with TRMM Precipitation Radar bright band data. J. Climate, 13, 4137-4148, 2000.

Hollinger, J.P., J.L. Peirce, and G.A. Poe, SSM/I instrument evaluation. IEEE Trans. Geosci. and Remote Sens., 28, 781-790, 1990.

Jorgensen, D. P. and P. T. Willis, A Z-R Relationship for Hurricanes. J. App. Meteor., 21, 356366, 1982.

Katsaros K. B., P. W. Vachon, P. G. Black, P. P. Dodge, and E. W. Uhlhorn, Wind fields from SAR: could they improve our understanding of storm dynamics. John Hopkins APL Tech. Digest, 21, 86-93, 2000.

Landsea, C. W., C. Anderson, N. Charles, G. Clark, J. Dunion, J. Fernandez-Partagas, P. Hungerford, C. Neumann, and M. Zimmer, The Atlantic hurricane database re-analysis project: Documentation for the 1851-1910 alterations and additions to the HURDAT 
database. In "Hurricanes and Typhoons: Past, Present and Future", R. J. Murname and K.-B. Liu, Eds., Columbia University Press, 177-221, 2004.

Lonfat, M., F. D. Matks, and S. S. Chen, Precipitation distribution in tropical cyclones using the Tropical Rainfall Measuring Mission (TRMM) Microwave Imager: a global perspective. Mon. Wea. Rev., 132, 1645-1660, 2004.

Marshall, J.S. and W. McK. Palmer, The distribution of raindrops with size, J. Meteor. 5, 165-166, 1948.

Ménard, Y., L-L. Fu, P. Escudier, F. Parisot, J. Perbos, P. Vincent, S. Desai, B. Haines, G. Kunstmann, The Jason-1 Mission. Marine Geodesy, 26, 131-146, 2003.

Monahan E., and I.G. O'Muircheartaingh, Optimal power-law description of oceanic whitecap coverage dependence on wind speed. J. Phys. Ocean., 10, 2094-2099, 1980.

Powell, M. D., S. H.Houston, and T. A. Reinhold, Hurricane Andrew's Landfall in South Florida. Part I: Standardizing measurements for documentation of surface wind fields. Weath. Forecast., 11, 304-328, 1996.

Powell, M. D., S. H. Houston, L. R. Amat, N. Morisseau-Leroy, The HRD real-time hurricane wind analysis system. J. Wind Engineer. Ind. Aerody., 77-78, 53-64, 1998.

Quartly G. D., Achieving accurate altimetry across storms: improved wind and wave estimates from C band. J. Atmos. Ocean. Tech., 14, 705-715, 1997.

Quartly G. D., Understanding the effects of rain on radar altimeter waveforms data: Part I: Theory. J. Atmos. Ocean. Technol., 15, 1361-1378, 1998.

Quilfen, Y., B. Chapron, T. Elfouhaily, K. Katsaros, J. Tournadre, Structures of tropical cyclones observed by high resolution scatterometry. J. Geophys. Res., 103, 7,767-7,777, 1998. 
Reul, N., and B. Chapron, A model of sea-foam thickness distribution for passive microwave remote sensing applications. J. Geophys. Res.,108, C10, 3321, doi:10.1029/2003JC001887, 2003.

Simpson, J., R. F. Adler, and G. R. North, Proposed Tropical Rainfall Measuring Mission (TRMM) satellite. Bull. Amer. Meteor. Soc., 69, 278295, 1988.

Tournadre J., Determination of rain cell characteristics from the analysis of TOPEX altimeter echo waveforms. J. Atmos. Ocean. Tech., 15, 387-406, 1998.

Tournadre, J., and Y. Quilfen, Impact of rain cell on scatterometer data: 1. Theory and modeling. J. Geophys. Res., 108, C7, 3225, doi:10.1029/2002JC001428, 2003.

Tournadre, J., Validation of Jason and Envisat altimeters dual frequency rain flags, $M a-$ rine Geodesy, 27, 153-170, 2004.

Tsai, W.Y., Dunbar, S., Freilich, M., Graf, J., Huddleston, J., Jones, L., Long, D., Wentz, F., Winn, C., Post-launch Sensor Verification and Calibration of the NASA Scatterometer. IEE Trans. GeoSci. Remote Sens., 37 1517-1542, 1999.

Ulaby, F. T., R. K. Moore and A. K. Fung, Microwave remote sensing: fundamentals and radiometry, Artech House, Norwood, Mass.,1981.

Willoughby, H. E., and M. E. Rahn, Parametric representation of the primary hurricane vortex. Part I: Observations and evaluation of the Holland (1980) model. Mon. Wea. Rev., 132, 3033-3045, 2004.

Witter, D.L., and D.B. Chelton, A Geosat wind speed algorithm and a method for altimeter wind speed algorithm development. J. Geophys. Res., 96, 8853-8860, 1991.

Young, I. R., An estimate of the Geosat altimeter wind speed algorithm at high wind speeds. J. Geophys. Res., 98, 20,275-20,285, 1993. 
Zheng Q. A., V. Klemas, G. S. Hayne and N. E. Huang, The effect of oceanic whitecaps and foams on pulse-limited radar altimeters. J. Geophys. Res., 88, 2571-2578, 1983. 


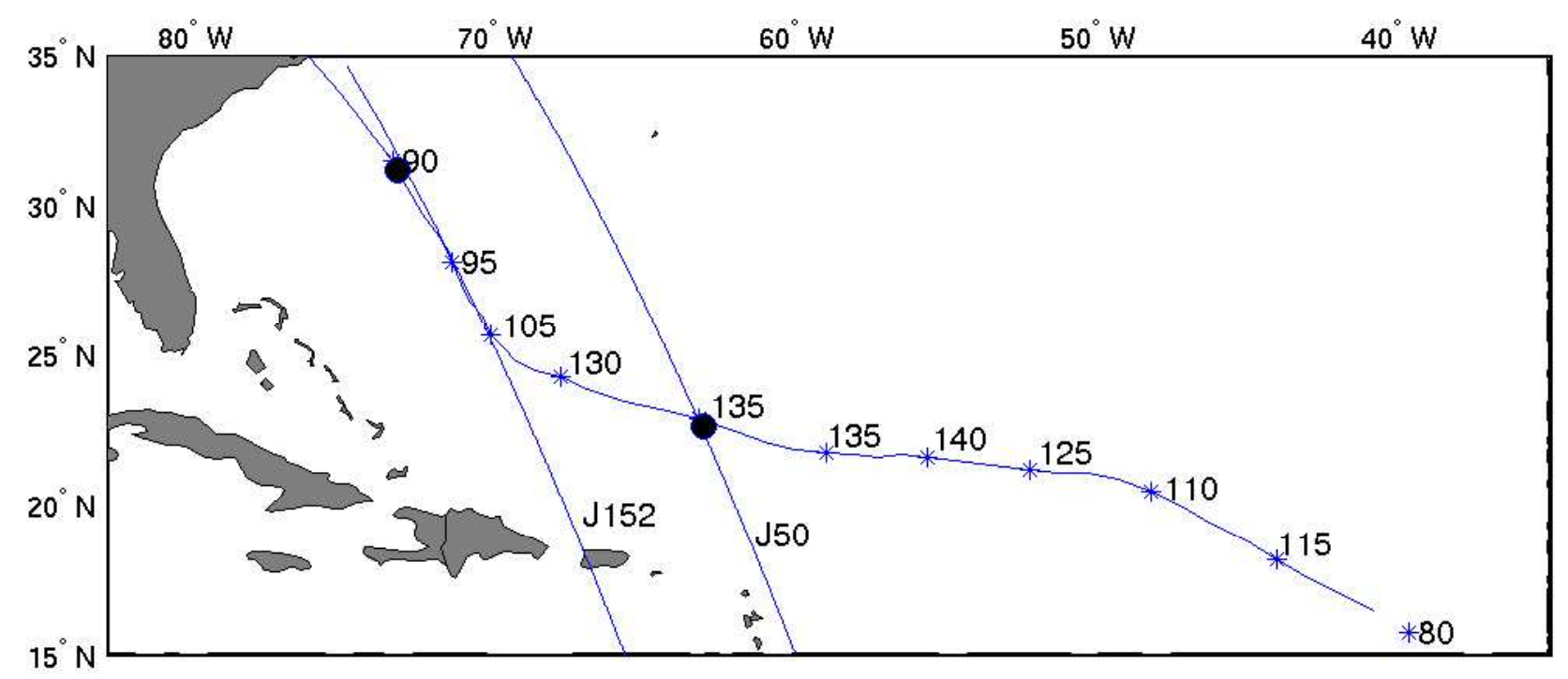

Figure 1. TC Isabel best track as determined by the Hurricane Research Division, and the two Jason orbits J50 and J152. The stars and numbers close to the Isabel track indicate Isabel location and maximum $1 \mathrm{mn}$ wind estimates (knots) each day at 00:00 UTC, starting on september 8th, 2003. The two black circles indicate the estimated Isabel location at Jason times. 

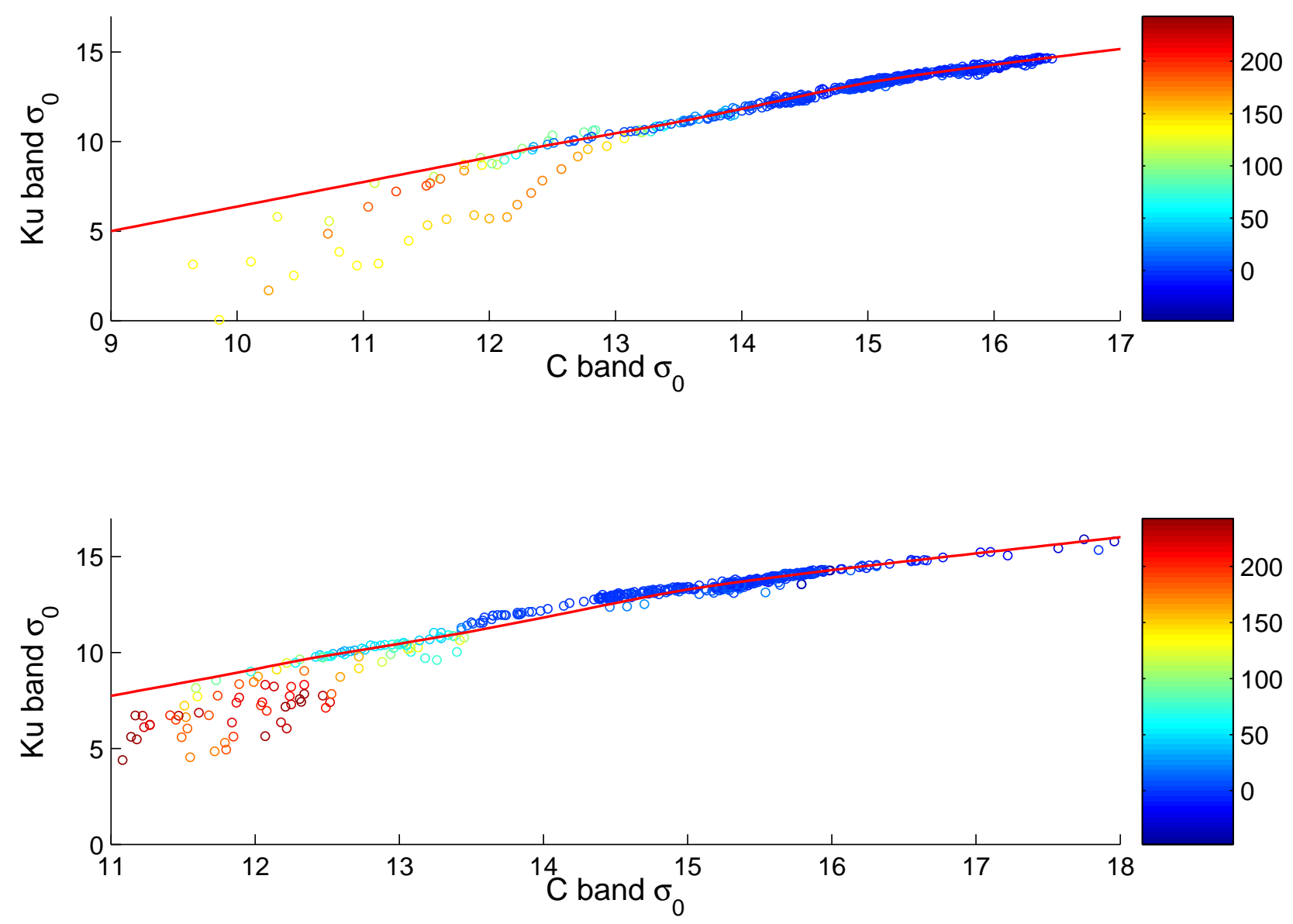

Figure 2. Ku-band NRCS (dB) as a function of C-band NRCS (dB) for Jason orbits 50 (top) and 152 (bottom). The color scale is a function of the JMR liquid water content $\left(0.01 \mathrm{~kg} \mathrm{~m}^{-2}\right)$. The red line is the mean rain free $\mathrm{C} / \mathrm{Ku}$ NRCS relationship. 

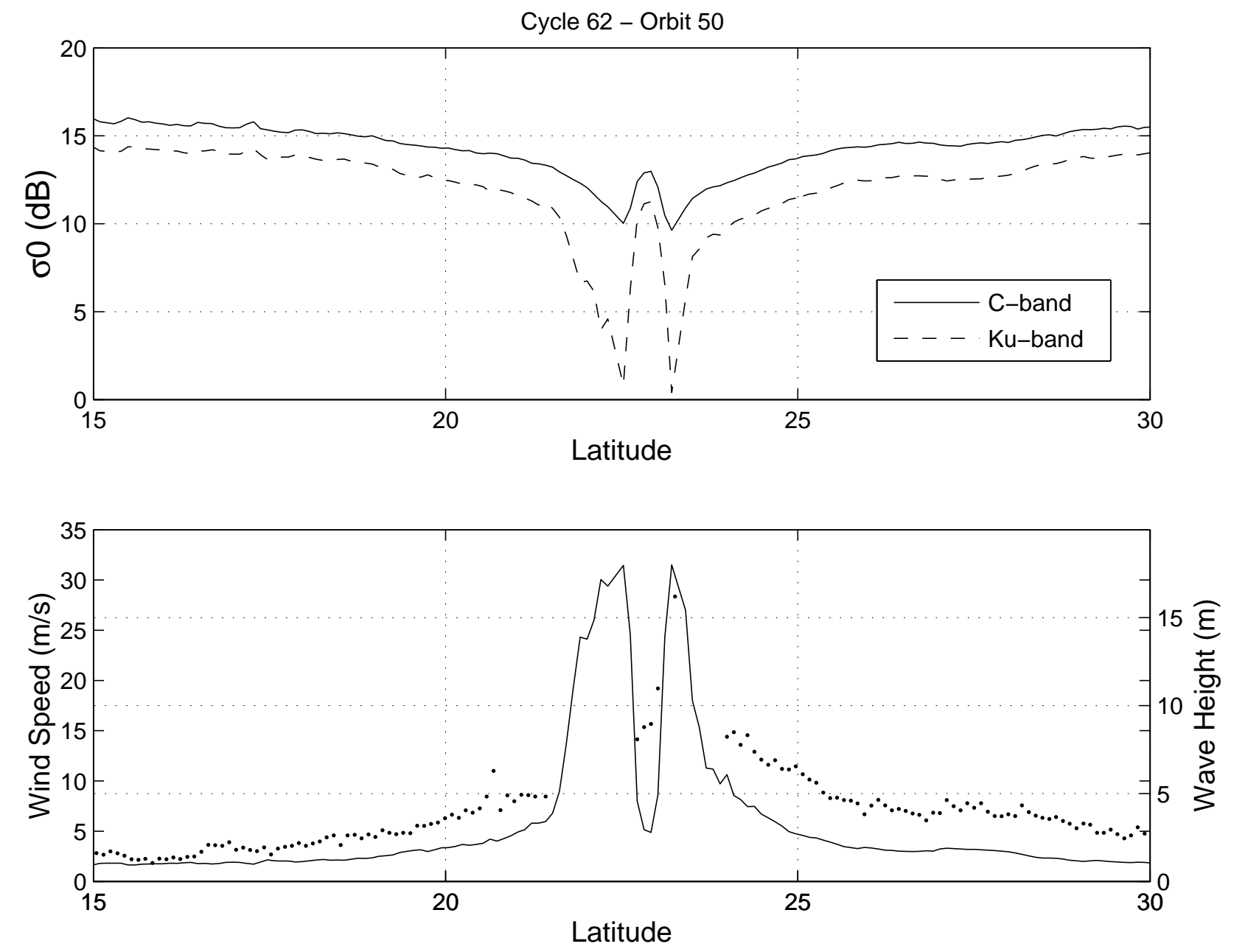

Figure 3. Ku and $\mathrm{C}$ band NRCS (top), and wind speed (bottom, solid line) and wave height (bottom, dotted line) for Jason orbits 50. All measurements are displayed along track, except rain flagged measurements for wave height. 

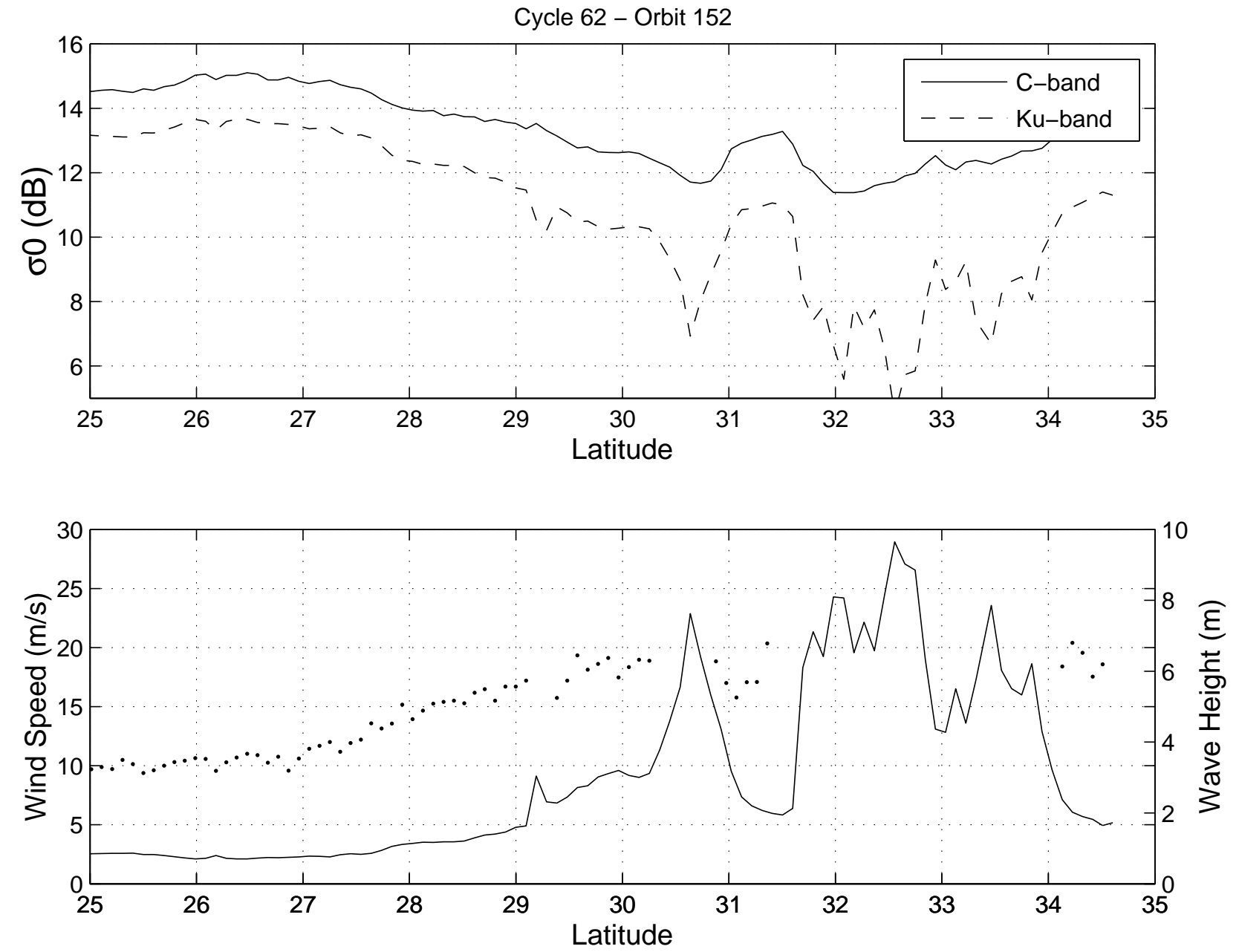

Figure 4. $\mathrm{Ku}$ and $\mathrm{C}$ band NRCS (top), and wind speed (bottom, solid line) and wave height (bottom, dotted line) for Jason orbits 152. All measurements are displayed along track, except rain flagged measurements for wave height. 

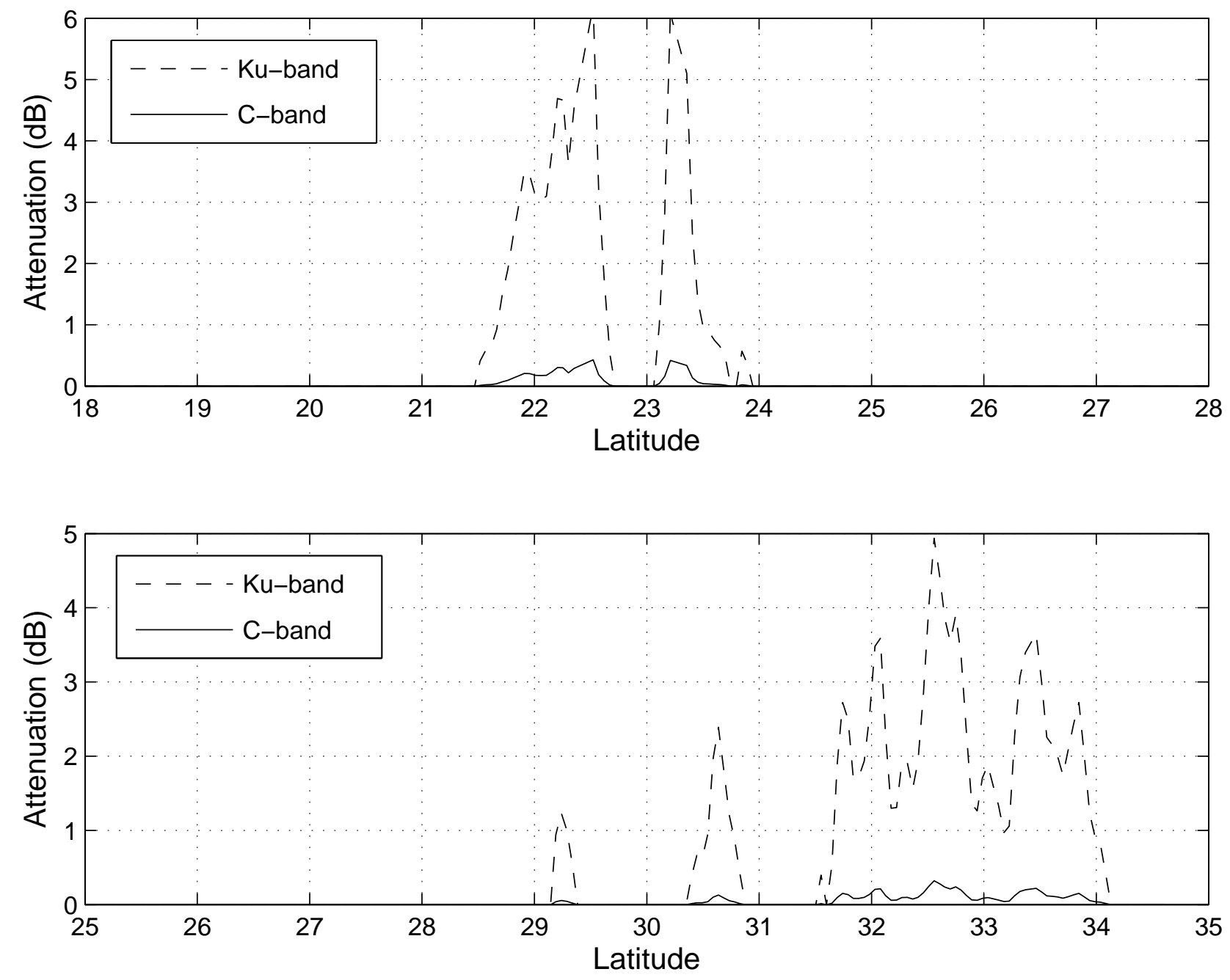

Figure 5. Ku and C band NRCS attenuation for Jason orbit 50 (top) and 152 (bottom). 

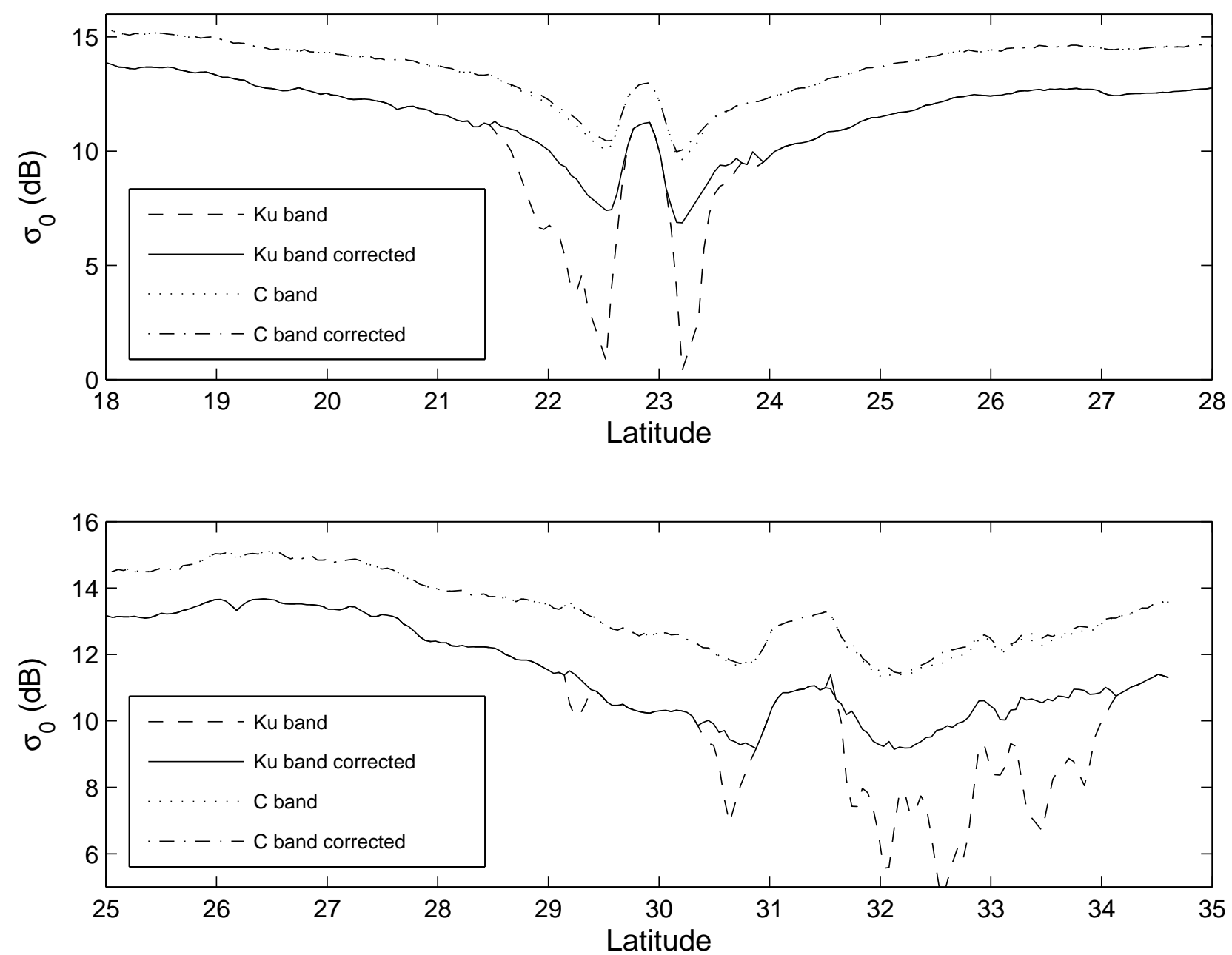

Figure 6. Measured (dashed line) and corrected (solid line) Ku band NRCS, and measured (dotted) and corrected (dashdot) C band NRCS for Jason orbit 50 (top) and 152 (bottom). 

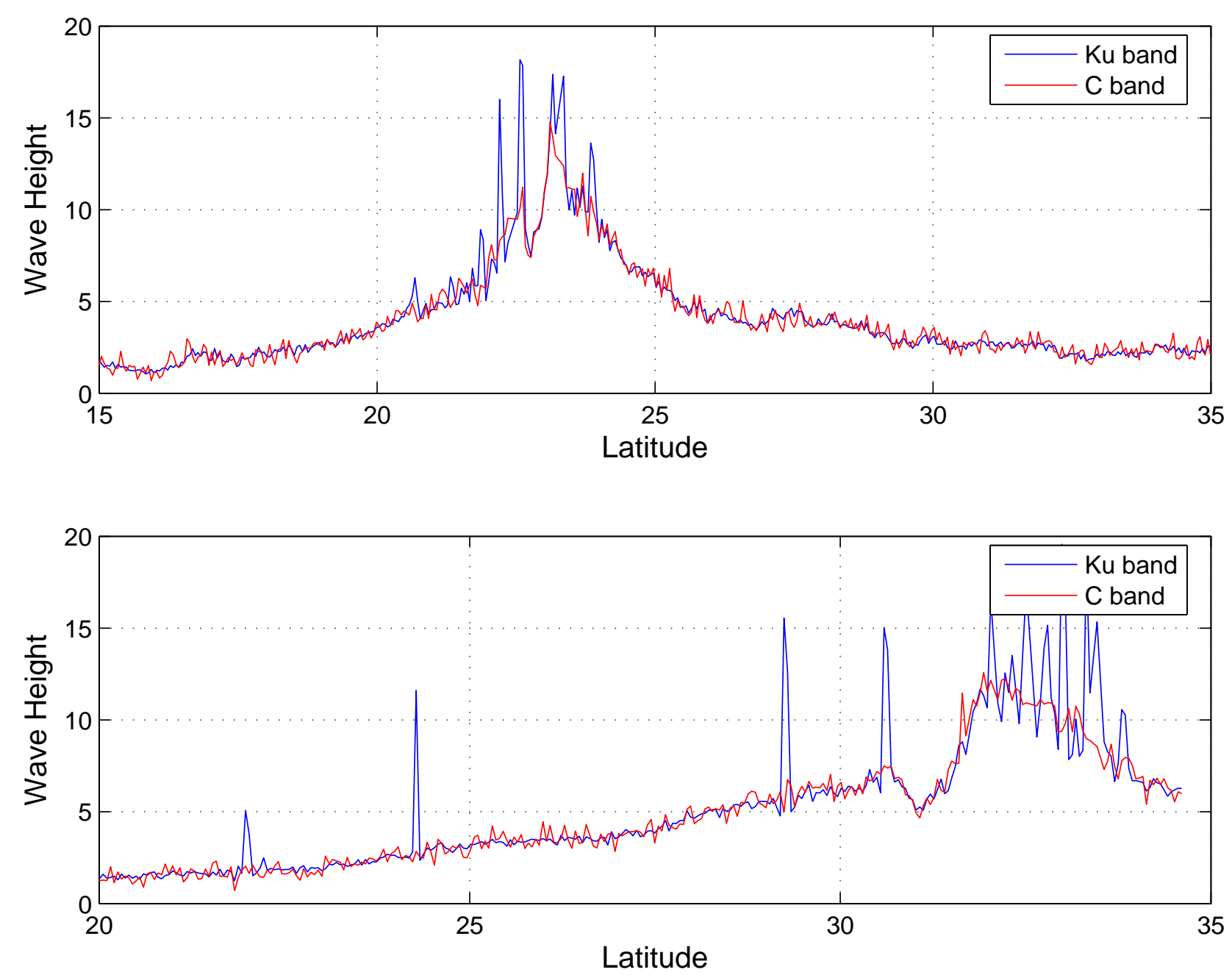

Figure 7. $\mathrm{Ku}$ and $\mathrm{C}$ band significant wave height (SWH) in meters for Jason orbit 50 (top) and 152 (bottom). 


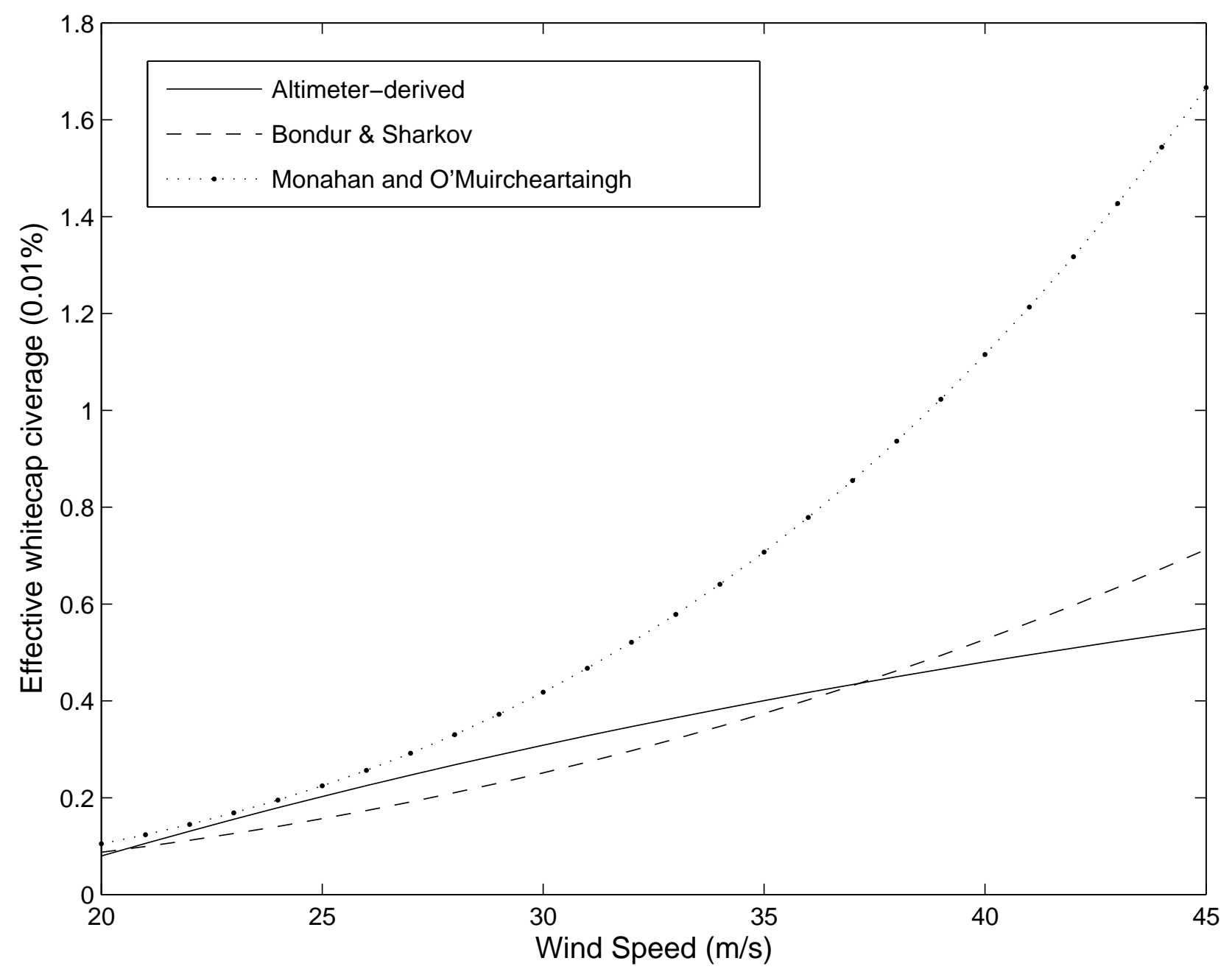

Figure 8. Effective whitecap coverage $(0.01 \%)$ as a function of wind speed $(\mathrm{m} / \mathrm{s})$ derived from equation 8 (solid line), Bondur and Sharkov (1982, dashed line), Monahan and O'Muircheartaingh (1980, dotted line). 

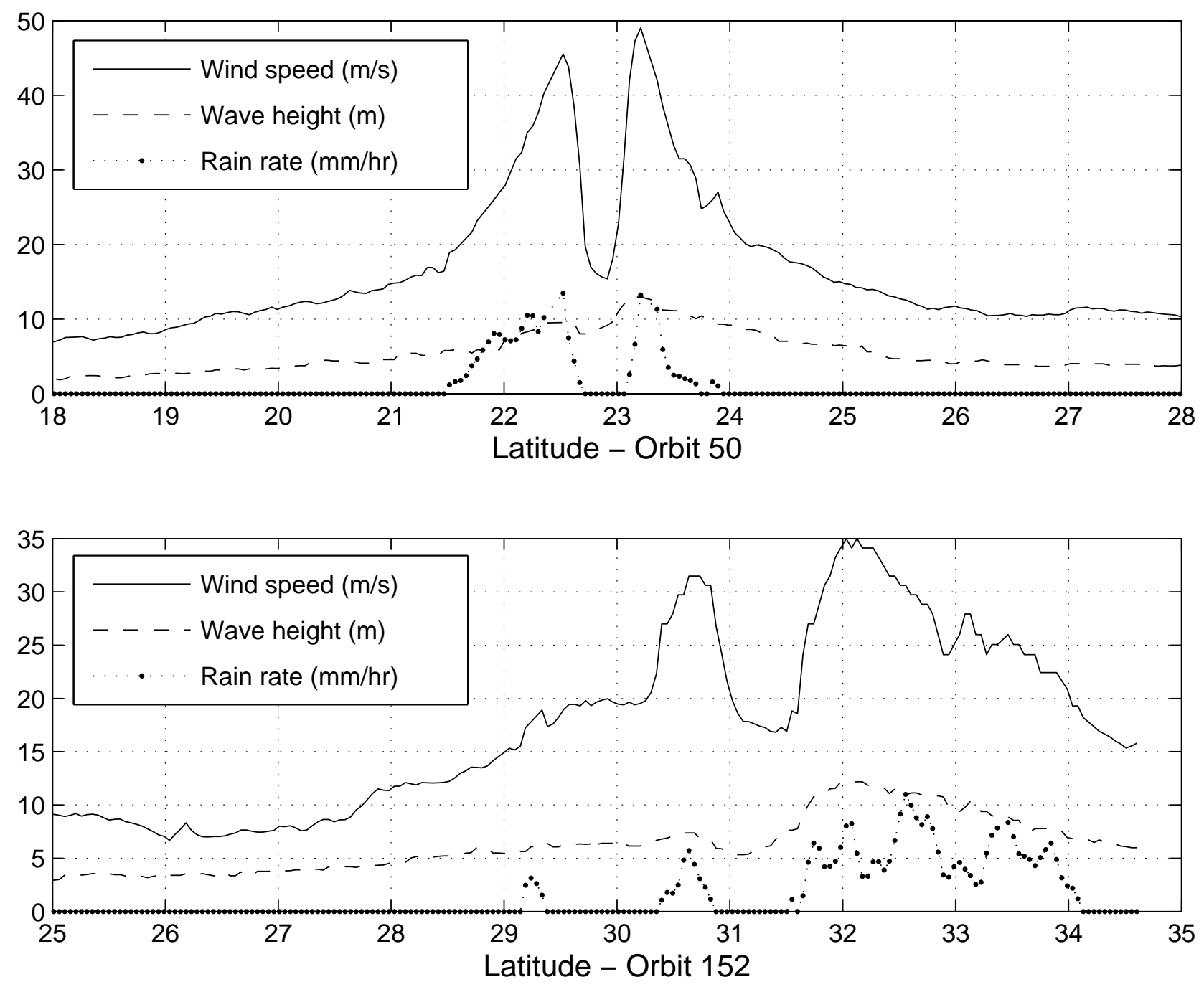

Figure 9. Wind speed $\left(\mathrm{m} \mathrm{s}^{-1}\right)$, significant wave height $(\mathrm{m})$, and rain rate $\mathrm{mm} h r^{-1}$ for Jason orbit 50 (top) and 152 (bottom). 

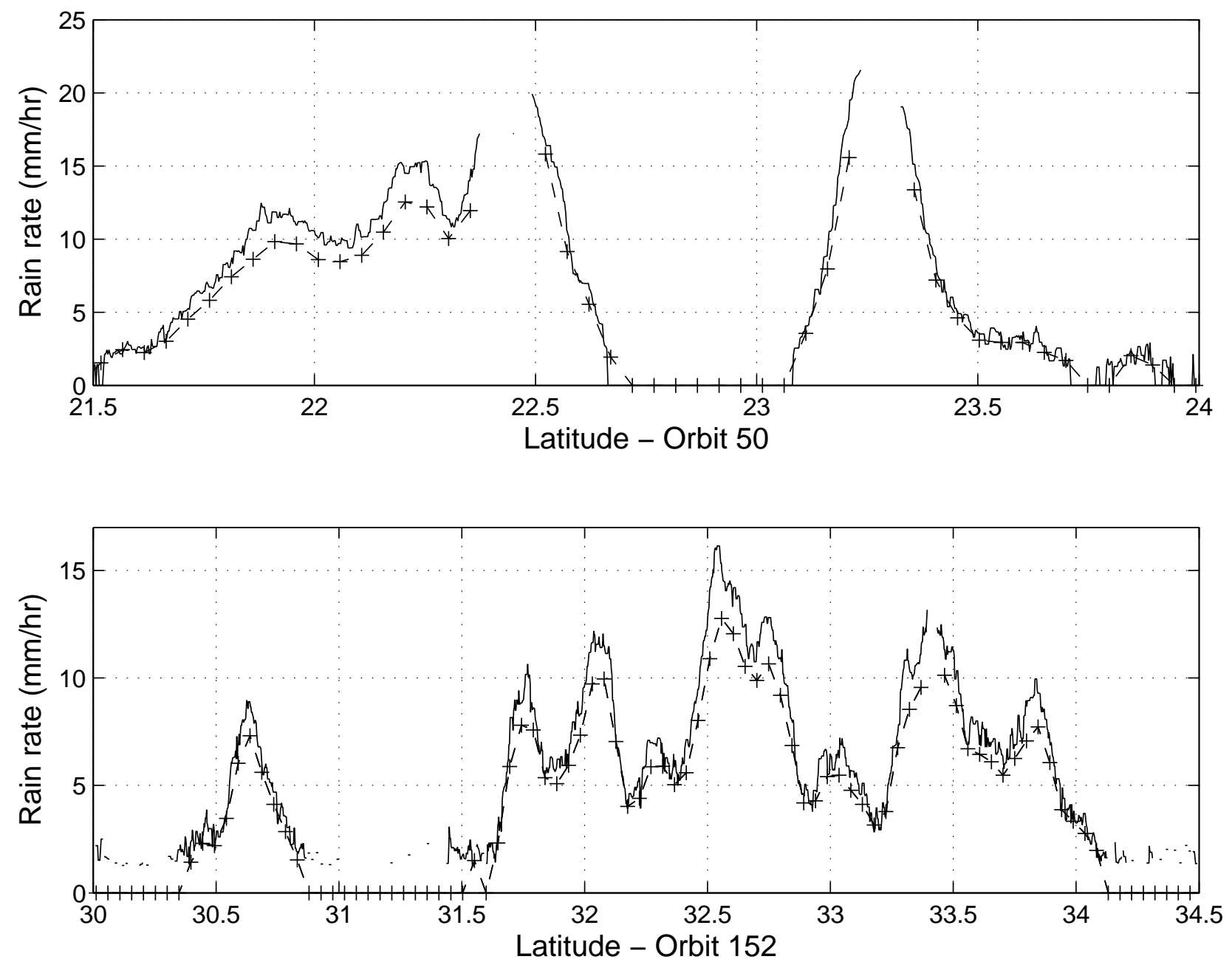

Figure 10. Rain rate $\left(m m h r^{-1}\right)$ for Jason orbit 50 (top) and 152 (bottom) computed from the low (dashed-plus line) and high (solid line) resolution measurements. 

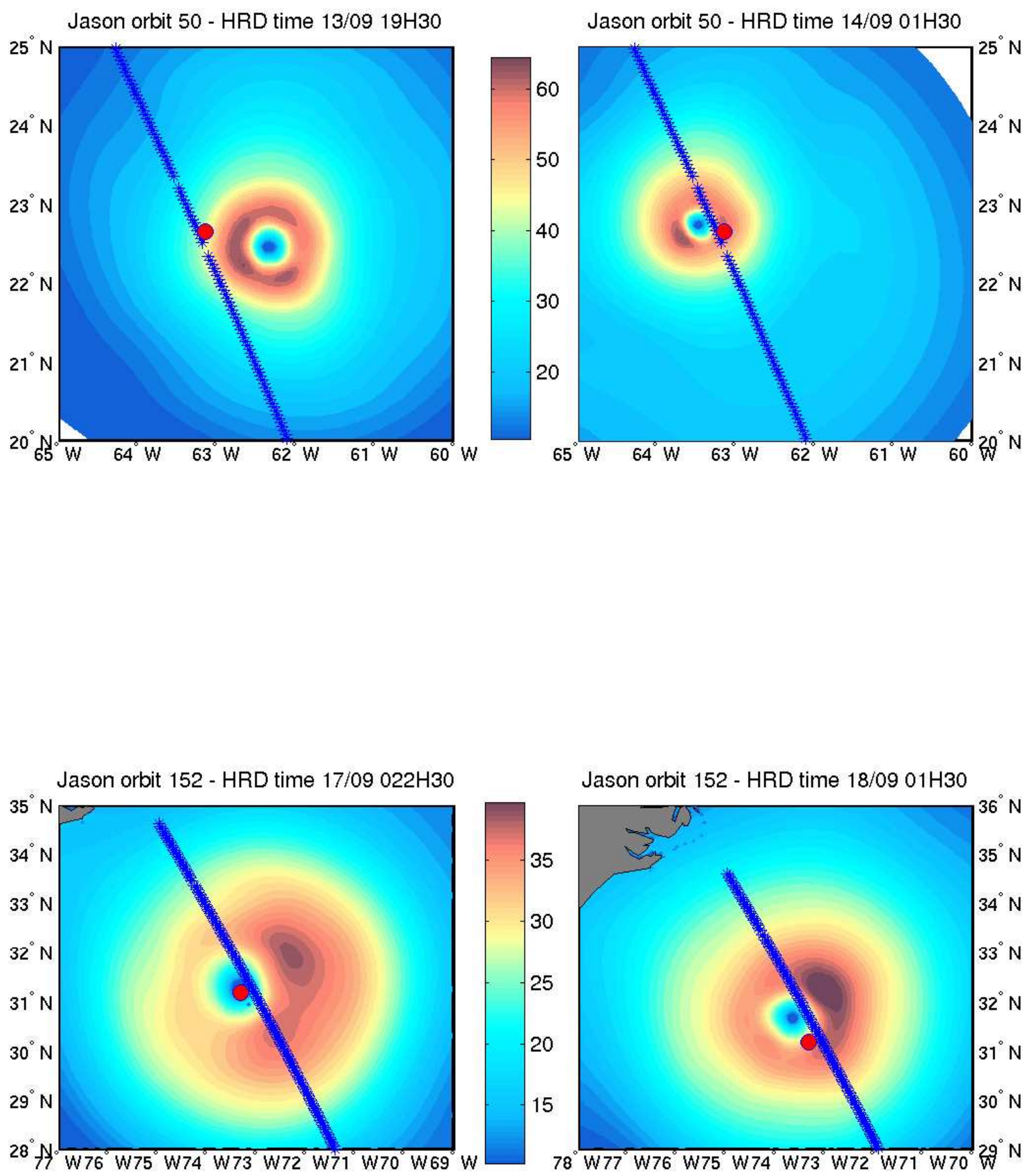

Figure 11. HRD wind speed analysis $\left(\mathrm{m} \mathrm{s}^{-1}\right)$ and Jason ground tracks for orbits 50 (top) and 152 (bottom). The HRD analyses are for time before the Jason one (left) and after the Jason one (right). The red circles indicates the Isabel center location estimate at Jason time. 

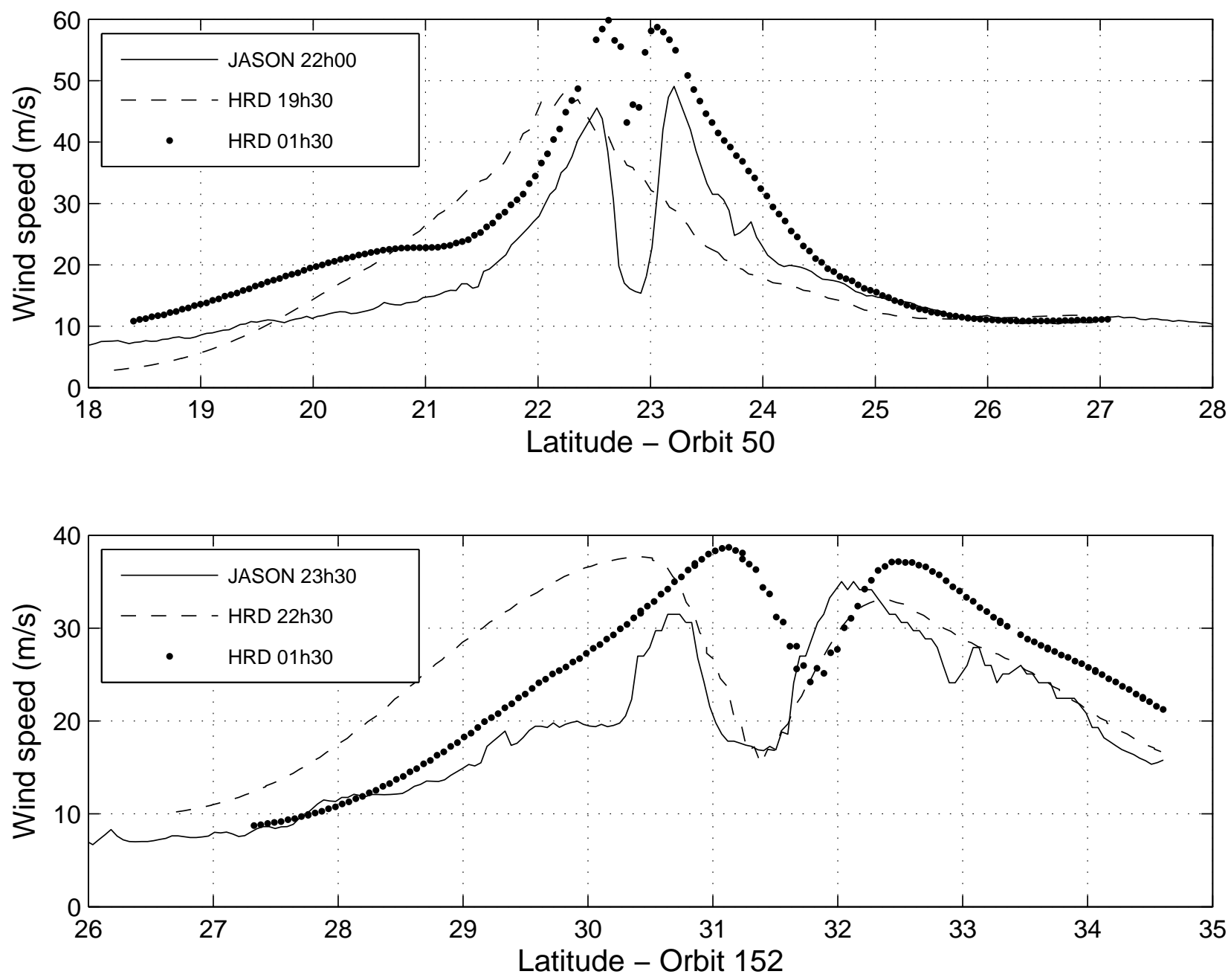

Figure 12. HRD and Jason wind speed (solid line, Young algorithm) for orbits 50 (top) and 152 (bottom). The HRD wind analyses are given for time before the Jason one (dashed line) and after the Jason one (dotted line). 
Table 1. JASON and closest HRD information for the two studied cases

\begin{tabular}{lcccccc}
\hline Cycle & Orbit & JASON date & HRD date & Latitude & Longitude & Max Wind (knts) \\
\hline 62 & 50 & Sept 13th 23:51 & Sept 14 00:00 & 22.9 & 63.3 & 135 \\
62 & 152 & Sept 17th 23:25 & Sept 18 00:00 & 31.5 & 73.5 & 90 \\
\hline
\end{tabular}

